\title{
Hubungan Tinggi Alveolar Mandibula Terhadap Retensi Gigi Tiruan Penuh Pada Pasien Rumah Sakit Gigi dan Mulut Universitas Andalas
}

\author{
Salsabilla Septia ${ }^{1}$, Eni Rahmi ${ }^{1}$, Bambang $^{1}$ \\ Korespondensi : Eni Rahmi; eni.rahmi@dent.unand.ac.id; Telp. 08113579513
}

\begin{abstract}
Background: Complete denture wearers were mostly complained with the uncomfortable and less retention of their denture especially mandibular denture. Alveolar ridge resorption leads to decrease in the size of denture-bearing area, therefore reducing denture retention. There are many factors that cause loss retention, which are closely related to alveolar ridge height. The aim of the study is to determine the relationship between mandibular residual ridge height and complete denture retention in Andalas Dental Collage and Hospital. Methods: This study used a cross sectional design, with total sampel of 30 complete denture wearers. Samples was selected through Consecutive Sampling Method. Data was collected by using medical record, panoramic radiograph, and denture retention examination that were analyzed by Chi-Square test with $p<0.05$. Results: There was not a significant relationship between mandibular residual ridge height and denture retention ( $p>0.05$ ). The conclusion of this study was the denture retention is not associated with mandibular residual ridge height in Andalas Dental Collage and Hospital.
\end{abstract}

Keywords: mandibular residual ridge, retention, complete denture.

Affiliasi penulis : ${ }^{1}$ Fakultas Kedokteran Gigi, Universitas Andalas

PENDAHULUAN

Kehilangan gigi merupakan salah satu permasalahan yang paling sering terjadi pada masyarakat sehingga bisa dijadikan ukuran terhadap status kesehatan mulut. Kehilangan gigi yang dibiarkan terlalu lama, mengakibatkan gigi asli yang tersisa migrasi, rotasi, erupsi yang berlebih (over eruption), pembebanan yang berlebih (over loading), dan mempengaruhi penampilan sehingga menyebabkan hilangnya kepercayaan diri. Selain itu kehilangan gigi akan berdampak terhadap sistem mastikasi, sendi temporomandibular dan gangguan fungsi bicara yang dapat mempengaruhi kualitas hidup seseorang 1,2,3.

Data Riset Kesehatan Dasar tahun 2018, menunjukkan masalah kesehatan gigi dan mulut di Indonesia yang paling banyak ditemukan gigi rusak/berlubang/sakit sebesar $45,3 \%$ dan gigi hilang karena dicabut/tanggal sendiri sebesar $19,0 \%$, sedangkan di Sumatera Barat, masalah gigi yang hilang karena dicabut/tanggal sendiri sebesar $19,6 \%$. Tindakan yang paling banyak diterima di Indonesia dalam 1 tahun terakhir untuk mengatasi masalah tersebut adalah pengobatan/minum obat sebesar $52,9 \%$, pencabutan gigi sebesar 7,9\% dan penambalan sebesar 4,3\%, sedangkan di Sumatera Barat, tindakan yang banyak diterima adalah pengobatan/minum obat sebesar $47,3 \%$, pencabutan gigi sebesar $7,4 \%$, dan penambalan sebesar $3,3 \%{ }^{4}$. Data tersebut sesuai dengan jumlah pelayanan pencabutan gigi permanen yang lebih banyak dibanding pelayanan berupa tumpatan di Puskesmas sekota Padang yaitu sebanyak 6.156 pencabutan dan 4.473 orang tumpatan gigi tetap, sehingga dapat dikatakan bahwa di Kota Padang 
banyak pasien yang kehilangan gigi dibanding pasien yang mempertahankan giginya dengan perawatan tambalan ${ }^{5}$.

Orang dewasa minimal harus memiliki 20 gigi yang berfungsi dengan baik untuk dapa tmempertahankan fungsi pengunyahan, fungsi estetik, dan fungsi bicara ${ }^{6}$. Penggantian gigi yang hilang dengan gigi tiruan merupakan hal yang penting bagi pasien untuk mengembalikan estetik maupun fungsional. Pengguna gigi tiruan banyak ditemukan pada usia 65 tahun keatas yaitu sebesar 4,1\%, baik gigi tiruan cekat atau gigi tiruan lepasan ${ }^{4}$. Gigi tiruan sebagian lepasan (GTSL) yang diindikasikan untuk menggantikan beberapa gigi dan gigi tiruan penuh (GTP) yang di indikasikan untuk menggantikan seluruh gigi. Penelitian Khoman (2012), pengguna GTSL sebagian besar ditemukan pada kelompok usia 21-40 tahun yaitu sebesar $54,5 \%$, sedangkan pengguna GTP sebagian besar ditemukan pada kelompok usia diatas 60 tahun yaitu sebesar $16,9 \%{ }^{7}$.

Hal yang perlu diperhatikan dalam pembuatan gigi tiruan adalah kontak gigi tiruan tersebut dengan jaringan disekitarnya dan dukungan atau landasan yang baik dari linggir alveolar. Tinggi linggir alveolar yang cukup akan menahan gerakan gigi tiruan dan dinding lateral linggir alveolar yang tertutupi oleh basis gigi tiruan dapat menahan gerakan lateral serta membentuk peripheral seal ${ }^{8} 9$. Faktor lain yang mempengaruhi keberhasilan GTP selain adanya jaringan pendukung yang memadai yaitu memiliki retensi yang cukup baik, kualitas dan kuantitas saliva, serta terdapat oklusi dan artikulasi yang seimbang ${ }^{10}$.

Beberapa keluhan sering dirasakan oleh pengguna gigi tiruan, berupa rasa kurang nyaman, longgarnya gigi tiruan, dan rasa sakit pada saat pemakaian gigi tiruan. Rasa longgar tersebut dapat dijumpai dengan terlihatnya gigi tiruan yang tidak cekat dan bergeser dari jaringan pendukung, terutama pada GTP rahang bawah yang terlihat naik atau terangkat saat digunakan ${ }^{8}$. Menurut penelitian Perea (2013), lokasi gigi tiruan berpengaruh terhadap tingkat kepuasan pasien. Gigi tiruan rahang bawah lebih sering menyebabkan rasa kurang nyaman pada pasien ${ }^{11}$.

Gigi tiruan yang longgar disebabkan oleh sebagian jaringan pendukung mengalami resorpsi sehingga menyebabkan kehilangan retensi dan stabilisasi. Resorpsi linggir alveolar dapat menyebabkan berkurangnya ukuran linggir sehingga luas daerah dukungan gigi tiruan penuh menjadi lebih kecil. Berkurangnya luas jaringan pendukung gigi tiruan dapat mempengaruhi faktor-faktor retensi yang bekerja pada permukaan basis gigi tiruan penuh antara lain adhesi, kohesi, tegangan permukaan, dan tekanan atmosfer. Jika linggir alveolar masih tinggi, gigi tiruan akan tertahan karena jaringan pendukungnya masih cukup luas tetapi pada linggir yang sudah datar, gigi tiruan akan mudah lepas karena perlekatan otot terletak dekat puncak linggir ${ }^{12}$.

Resorpsi linggir alveolar biasa disebut juga dengan residual ridge resorption (RRR). Residual ridge resorption merupakan proses resorpsi yang berkelanjutan seumur hidup, terjadi pada enam bulan setelah pencabutan gigi dan berangsur-angsur berkurang. Menurut penelitian Lopez-Roldan (2009), menyatakan bahwa resorpsi linggir alveolar mandibula 2.5 kali lebih besar dibanding resorpsi maksila ${ }^{13}$. Penelitian tersebut sama dengan hasil yang diperoleh Al-Jabrah (2014) dan Kumar (2016), menyatakan bahwa resorpsi linggir alveolar mandibula lebih cepat dibanding maksila ${ }^{14}{ }^{15}$. Menurut penelitian Kovacic (2011), bagian anterior mandibula menunjukkan derajat resorpsi yang tinggi, berbeda dengan hasil penelitian 
Enlow (1976), menyatakan bahwa resorpsi linggir alveolar mandibula lebih cepat terjadi didaerah premolar dan molar dari pada bagian anterior ${ }^{16} 17$.

Faktor yang menyebabkan resorpsi linggir alveolar adalah faktor lokal dan sistemik. Faktor lokal seperti retensi dan stabilisasi gigi tiruan yang tidak baik sehingga menekan linggir alveolar melalui kontak oklusal, relasi vertikal dan horizontal gigi tiruan yang salah, penggunaan gigi tiruan dimalam hari, oklusi yang tidak seimbang, dan lama pemakaian gigi tiruan ${ }^{14} 18$.

Menurut penelitian Campbell (1960), pasien yang menggunakan GTP menunjukkan linggir alveolar yang lebih rendah dibanding pasien tanpa perawatan gigi tiruan. Tingkat resorpsi mandibula lebih tinggi dibanding maksila pada pasien GTP ${ }^{19}$. Hasil ini sama dengan penelitian Al Jabrah (2014), resorpsi linggir alveolar mandibula akan meningkat seiring dengan peningkatan durasi pemakaian GTP ${ }^{14}$. Penelitian Samyukta (2016), laju resorpsi linggir alveolar dua kali lebih jelas pada mandibula dari pada maksila setelah 5 tahun pemakaian GTP20. Penelitian Babu (2017), menunjukkan terjadi resorpsi linggir sekitar 0.3-1.2 mm setelah 6 bulan pemakaian gigi tiruan ${ }^{21}$.

Faktor sistemik yang mempengaruhi resorpsi linggir alveolar antara lain yang bersifat patologis dan fisiologis. Faktor patologis yang berpengaruh terhadap resorpsi antara lain ketidakseimbangan hormon, gangguan hormonal paska menopos pada wanita, asupan kalsium yang rendah, dan penyakit diabetes melitus, sedangkan faktor fisiologis seperti usia dan jenis kelamin. Berdasarkan jenis kelamin, penelitian Abdulhadi (2009) mendapatkan hasil bahwa wanita beresiko mengalami resorpsi linggir alveolar 2 kali lebih tinggi dibanding laki-laki ${ }^{18}$. Berdasarkan usia, penelitian Jayaram (2017) melaporkan bahwa pada usia diatas 60 tahun, resorpsi linggir mandibula lebih cepat dibanding pada usia muda 40-60 tahun ${ }^{22}$. Hasil penelitian tersebut sama dengan hasil yang didapatkan Al Sheikh (2018), yang menyatakan hubungan peningkatan usia dengan resorpsi linggir, yaitu ketika usia seseorang semakin meningkat maka tinggi linggir akan semakin menurun ${ }^{23}$.

Resorpsi linggir alveolar yang berkelanjutan akan menyebabkan perubahan bentuk pada linggir tersebut. Menurut Zarb (2013), bentuk linggir alveolar berpengaruh terhadap dukungan pada gigi tiruan penuh. Tulang dengan bentuk membulat dan sedikit persegi pada regio labial, bukal, dan lingual serta ditutupi oleh perlekatan mukosa yang baik ${ }^{9}$.

Hasil yang berbeda dilaporkan oleh Ribeiro (2014), yang menyatakan bentuk linggir alveolar rahang bawah tidak mempengaruhi kekuatan retensi tetapi kelenturan mukosa tulang alveolar yang mempengaruhi retensi. Bentuk linggir alveolar rahang bawah lebih berpengaruh terhadap stabilitas gigi tiruan sedangkan kelenturan mukosa linggir alveolar tidak mempengaruhi stabilisasi gigi tiruan ${ }^{24}$. Penelitian tersebut sama dengan hasil penelitian Celebic (2003), menyatakan bahwa pasien dengan kualitas linggir yang baik memberikan penilaian buruk terhadap retensi gigi tiruan mandibula, kemampuan pengunyahan, dan kenyamanan penggunaan gigi tiruan mandibula dibandingkan dengan pasien dengan kualitas linggir yang buruk ${ }^{25}$.

Penelitian Zeng (2011), menunjukkan bahwa tinggi dan daerah penahan tekanan pada linggir alveolar mandibula berhubungan langsung dengan retensi GTP26. Penilaian kepuasan gigi tiruan dan hubungannya dengan kualitas linggir ini memberi hasil yang sama dengan penelitian Pan(2010), yang 
menunjukkan perbedaan tiap kategori berdasarkan kategori American Collage Prosthodonti terhadap tingkat kepuasan pasien berupa rasa nyaman, stabilisasi, dan kemampuan mengunyah ${ }^{27}$.

\section{METODE}

Penelitian ini bertujuan untuk mengetahui hubungantinggi linggir alveolar mandibula dengan retensi gigi tiruan penuh (GTP). Responden pada penelitian ini sebanyak 30 orang yang merupakan pasien Rumah Sakit Gigi dan Mulut Universitas Andalas (RSGM Unand) yang dibuatkan GTP dan telah menggunakannya maksimal setahun setelah insersi. Penelitian ini dilaksanakan selama empat belas hari, yaitu dimulai pada hari Senin, 8 Juli 2019 s/d 21 Juli 2019.

Pada penelitian ini dilakukan pemeriksaan variabel terkendali yaitu viskositas dan laju alir saliva serta panjang tepi sayap basis GTP. Pemeriksaan viskositas saliva dilakukan secara visual, pasien yang dijadikan responden memiliki viskositas saliva yang tidak terlalu kental dan juga tidak terlalu encer. Pemeriksaan laju alir saliva dilakukan dengan menginstruksikan pasien mengumpulkan saliva pada tube tiap 1 menit selama 5 menit dan laju alir saliva akan diukur dengan cara membagi jumlah saliva yang terkumpul dengan waktu yang sudah ditetapkan yaitu 5 menit, pasien yang dijadikan responden memiliki laju alir yang normal yaitu 2,6-3,5 ml/menit. Pemeriksaan panjang tepi sayap basis GTP dengan cara menginstruksikan responden menggerakkan pipi dan bibir sehingga didapatkan responden yang sesuai dengan kriteria inklusi dan eksklusi.

Hasil penelitian diolah menggunakan program SPSS 19, dengan melakukan analisis univariat untuk melihat distribusi masing-masing variabel dan analisis bivariat dengan uji statistik alternatif KolmogorovSmirnov untuk melihat hubungan antar variabel karena tidak memenuhi syarat uji Chi-square.

\section{HASIL DAN PEMBAHASAN}

Karakteristik responden pada penelitian ini meliputi jenis kelamin dan kelompok usia responden. Distribusi frekuensi responden berdasarkan jenis kelamin terlihat pada Tabel 1 dan distribusi frekuensi responden berdasarkan kelompok usia terlihat pada Tabel 2 .

Tabel 1. Distribusi frekuensi responden berdasarkan jenis kelamin

\begin{tabular}{ccc}
\hline Jenis Kelamin & Frekuensi (f) & Persentase (\%) \\
\hline Laki-laki & 14 & 46,7 \\
Perempuan & 16 & 53,3 \\
Total & 30 & 100,0 \\
\hline
\end{tabular}

Berdasarkan Tabel 1 dapat disimpulkan bahwa mayoritas responden yaitu sebanyak $53,3 \%$ berjenis kelamin perempuan. Hal ini dapat dikaitkan dengan kebutuhan yang tinggi akan penampilan, sehingga lebih banyak perempuan yang menggunakan GTP agar terlihat lebih estetik. 
ANDalas deNtal journal

Fakultas Kedokteran Gigi Universitas Andalas

Jalan Perintis Kemerdekaan No. 77 Padang, Sumatera Barat

Web: adj.fkg.unand.ac.id Email: adj@dent.unand.ac.id

Tabel 2. Distribusi frekuensi responden berdasarkan kelompok usia

\begin{tabular}{ccc}
\hline Usia & Frekuensi $(\mathfrak{f})$ & Persentase $(\%)$ \\
\hline$\leq 60$ tahun & 10 & 33,3 \\
$>60$ tahun & 20 & 66,7 \\
Total & 30 & 100,0 \\
\hline
\end{tabular}

Berdasarkan Tabel 2 dapat disimpulkan bahwa mayoritas responden sebanyak 66,7\% berusia diatas 60 tahun. Hal ini dikarenakan pengguna GTP lebih banyak pada usia 60 tahun keatas.

Tinggi linggir alveolar mandibula menurut American College of Prosthodontics dibagi menjadi 4 klas yaitu klas I dengan tinggi $\geq 21 \mathrm{~mm}$, klas II dengan tinggi $16 \mathrm{~mm}-20 \mathrm{~mm}$, klas III dengan tinggi $11 \mathrm{~mm}-15$ $\mathrm{mm}$, dan klas IV dengan tinggi $\leq 10 \mathrm{~mm}$. Distribusi frekuensi tinggi linggir alveolar mandibula responden terlihat pada Tabel 3.

Tabel 3. Distribusi frekuensi tinggi linggir alveolar mandibula

\begin{tabular}{ccc}
\hline Tinggi linggir alveolar mandibula & Frekuensi (f) & Persentase (\%) \\
\hline Klas I & 22 & 73,3 \\
Klas II & 8 & 26,7 \\
Klas III & - & - \\
Klas IV & - & - \\
Total & 30 & 100 \\
\hline
\end{tabular}

Berdasarkan Tabel 3 dapat dilihat bahwa responden dengan tinggi linggir alveolar mandibula klas I sebesar $73,3 \%$ atau sebanyak 22 orang. Hal ini menunjukkan bahwa linggir alveolar mandibula dengan tinggi $\geq 21 \mathrm{~mm}$ merupakan ukuran tinggi yang paling banyak ditemukan pada pengguna GTP di RSGM Unand.

Retensi GTP rahang bawah pada pasien RSGM Unand dikategorikan menjadi 4 kelompok yaitu baik, sedang, minimum, dan tidak ada retensi. Kategori tersebut adalah skor dari pemeriksaan retensi menggunakan timbangan digital yang dimodifikasi. Dalam penelitian ini munggunakan indeks skor menurut CU-modified Kapur Index. Distribusi frekuensi retensi GTP rahang bawah responden terlihat pada Tabel 4.

Tabel 4. Distribusi frekuensi retensi GTP rahang bawah

\begin{tabular}{ccc}
\hline Retensi GTP rahang bawah & Frekuensi (f) & Persentase (\%) \\
\hline Baik & 1 & 3,3 \\
Sedang & 9 & 30 \\
Minimum & 20 & 66,7 \\
Tidak ada retensi & - & - \\
Total & 30 & 100 \\
\hline
\end{tabular}

Berdasarkan Tabel 4 diketahui bahwa retensi GTP rahang bawah yang paling sering ditemukan adalah kategori minimum, yaitu sebesar $66,7 \%$ atau sebanyak 20 orang. Secara umum dapat disimpulkan 
Fakultas Kedokteran Gigi Universitas Andalas

Jalan Perintis Kemerdekaan No. 77 Padang, Sumatera Barat

Web: adj.fkg.unand.ac.id Email: adj@dent.unand.ac.id

bahwa kebanyakan GTP rahang bawah pasien RSGM Unand memiliki retensi yang minimum sehingga beberapa pasien mengeluhkan rasa kurang nyaman.

Tabel 5. Hubungan tinggi linggir alveolar mandibula dengan retensi GTP rahang bawah

\begin{tabular}{|c|c|c|c|c|c|c|c|c|c|}
\hline \multirow[b]{3}{*}{$\begin{array}{l}\text { Tinggi Linggir } \\
\text { Alveolar }\end{array}$} & \multicolumn{6}{|c|}{ Retensi GTP Rahang Bawah } & \multirow{2}{*}{\multicolumn{2}{|c|}{ Total }} & \multirow{3}{*}{$\mathrm{p}$} \\
\hline & \multicolumn{2}{|c|}{ Baik } & \multicolumn{2}{|c|}{ Moderate } & \multicolumn{2}{|c|}{ Minimum } & & & \\
\hline & $\mathrm{F}$ & $\%$ & $\mathrm{~F}$ & $\%$ & $\mathrm{~F}$ & $\%$ & $f$ & $\%$ & \\
\hline Klas I & 1 & 4,5 & 8 & 36,4 & 13 & 59,1 & 22 & 100,0 & 0,731 \\
\hline Klas II & - & - & 1 & 12,5 & 7 & 87,5 & 8 & 100,0 & \\
\hline Total & 1 & 3,3 & 9 & 30 & 20 & 66,7 & 30 & 100,0 & \\
\hline
\end{tabular}

Pada Tabel 5 diketahui nilai $p=0,731(p>0,05)$, maka dapat disimpulkan bahwa tidak terdapat hubungan antara tinggi linggir alveolar mandibula dengan retensi GTP rahang bawah pada pasien RSGM Unand.

Hasil uji statistik hubungan tinggi linggir alveolar mandibula terhadap retensi GTP menunjukkan bahwa nilai $p>0,05$, berarti dapat disimpulkan bahwa tidak terdapat hubungan yang bermakna. Hal ini terjadi karena pada linggir yang tingginya ideal, masih banyak ditemukan gigi tiruan rahang bawah yang kurang retentif. Walaupun demikian, responden beranggapan bahwa gigi tiruan yang tidak retentif terjadi karena linggir sudah mengalami resorpsi seiring bertambahnya usia, sehingga responden memaklumi jika gigi tiruan yang digunakan lama-kelamaan akan longgar dan responden tetap mengunakan gigi tiruan agar mereka bisa beradaptasi dengan keadaan gigi tiruannya.

Penelitian oleh Celebic et al (2003), mendapatkan hasil bahwa tidak ada hubungan antara tinggi linggir dengan retensi. Pasien dengan linggir alveolar yang baik dan daerah dukungan gigi tiruan yang cukup tetap memberikan penilaian buruk terhadap retensi. Pasien yang baru pertama menggunakan gigi tiruan dengan durasi yang sebentar dan masih memiliki daerah dukungan gigi tiruan yang cukup, memberikan penilaian yang rendah terhadap retensi gigi tiruan rahang bawah dibanding dengan pasien yang pernah menggunakan gigi tiruan sebelumnya dengan durasi yang lebih lama dan daerah dukungan gigi tiruannya yang sudah berkurang. Hal ini bisa disebabkan karena lamanya durasi adaptasi neuromuskular terhadap gigi tiruan rahang bawah dan durasi yang lama untuk otot lidah, pipi, bibir, dan mukosa yang mengelilingi gigi tiruan rahang bawah untuk beradaptasi dengan sayap gigi tiruan ${ }^{25}$.

Menurut penelitian Ribeiro et al (2014), bentuk dan ukuran linggir alveolar mandibula mempengaruhi stabilisasi gigi tiruan, sedangkan kelenturan mukosa linggir akan mempengaruhi retensi. Hal ini dikarenakan tinggi dan lebar linggir alveolar lebih berkaitan untuk menahan pergerakan gigi tiruan terhadap gaya rotasi, sedangkan kelenturan mukosa linggir menahan pergerakan gigi tiruan terhadap gaya vertikal. Banyak faktor yang mempengaruhi keberhasilan perawatan dengan gigi tiruan, sehingga karakteristik klinis dari linggir alveolar saja tidak bisa memprediksi keberhasilan perawatan ${ }^{24}$. 
Hasil penelitian ini berbeda dengan pendapat Zarb bahwa tinggi linggir alveolar yang cukup dapat menahan gerakan gigi tiruan dengan cara membatasi ruang gaya yang melepaskan dan dinding lateral linggir alveolar yang tertutup oleh basis gigi tiruan dapat menahan gerakan lateral ${ }^{9}$. Hal ini sejalan dengan penelitian Kumar et al yang melaporkan padalinggir alveolar yang tinggi, gigi tiruan akan tertahan karena jaringan pendukungnya luas, sedangkan pada linggir yang sudah datar, gigi tiruan akan mudah lepas karena perlekatan otot terletak dekat puncak linggir ${ }^{15}$.

\section{SIMPULAN}

Tinggi linggir alveolar mandibula pada pasien pengguna gigi tiruan penuh RSGM Unand adalah $\geq 21$ $\mathrm{mm}$. Retensi gigi tiruan penuh rahang bawah pada pasien pengguna gigi tiruan penuh RSGM Unand adalah retensi minimum. Tidak terdapat hubungan tinggi linggir alveolar mandibula dengan retensi gigi tiruan penuh pada pasien pengguna gigi tiruan penuh RSGM Unand.

\section{KEPUSTAKAAN}

1. Gunadi HA, M. A., Buku Ajar IImu Geligi Tiruan Sebagian Lepasan jilid I. In M. A. Gunadi HA, Buku Ajar IImu Geligi Tiruan Sebagian Lepasan jilid I. Jakarta: Hipokrates. 1993, pp. 11-47.

2. Gerritsen, A. E., et al., Tooth Loss and Oral Health-Related Quality of Life: A Systematic Review and Meta-Analysis. Health and Quality of Life Outcomes, 2010; 8: 126.

3. Bortoluzzi, Marcello Ccarlos., et al., Tooth Loss, Chewing Ability and Quality of Life.Contemporary Clinical Dentistry, Oct-Dec, 2012: Vol. 3(4).

4. Riskesdas. 2018. Badan Penelitian dan Pengembangan Kesehatan,Departemen Kesehatan Republik Indonesia.

5. Dinas Kesehatan Kota Padang, Laporan Tahunan Dinas Kesehatan Kota Padang Tahun 2017 Edisi Tahun 2018. Diakses dari https://dinkes.padang.go.id/read/234.

6. Kementerian Kesehatan R.I., Buku Panduan Pelatihan Kesehatan gigi dan Mulut Kader Posyandu. Jakarta. 2012.

7. Khoman, J. A., Mariati, N. W., dan Siagian, E. D., Profil Pemakaian Gigi Tiruan Lepasan Berbasis Akrilik Pada Masyarakat Kelurahan Bahu Kecamatan Malalayang. Jurnal Biomedik, 2012: Vol.4(1).

8. Basker, R. M., dan Davenport, J. C., Prosthetic Treatment of the Edentulous Patient Fourth Edition. Blackwell Munksgaard. 2002.

9. Zarb, H. E., Prosthodontic Treatment For Edentulous Patients 13th Edition. St. Louis: Mosby. 2013.

10. Grant AA, Heath JR, McCord JF, Complete prosthodontics: problems, diagnosis and management, C.V. Mosby, St Louis. 1995.

11. Perea C, S.-G. M., Oral Health-related Quality of Life in Complete Denture Wearers Depending on Their Socio-demographic Background, Prosthetic-related Factors and Clinical Condition . Med Oral Patol Oral Cir Bucal. 2013.

12. Yadav B, J. M., Comparison of Different Final Impression Techniques for Management of Resorbeb Mandibular Ridge: A Case Report. Case Report Dentistry. 2014. 
Fakultas Kedokteran Gigi Universitas Andalas

Jalan Perintis Kemerdekaan No. 77 Padang, Sumatera Barat

Web: adj.fkg.unand.ac.id Email: adj@dent.unand.ac.id

13. Lopez-Roldan, A., et al., Bone Resorption Processes in Patients Wearing Overdentures. A 6-years retrospective study. J Clin Exp Dent. 2009.

14. Al-Jabrah, O., Association of Type 2 Diabetes Mellitus with the Reduction of Mandibular Residual Ridge among Edentulous Patients using Panoramic Radiographs. Open Journal of Stomatology. 2011.

15. Kumar TA, N. A., Residual Ridge Resorption: The Unstoppable. J app Res. 2016.

16. Enlow DH, B. H., The Remodeling of The Edentulous Mandible.J Prosthet Dent. 1976.

17. Kovacic, I., Zlataric, D. K., dan Celebic, A., Residual Ridge Atrophy in Complete Denture Weares and Relationship with Densitometric Values of a Cervical Spine: A Hierarchical Regression Analysis. The Gerodontology Society and John Wiley\&Son. 2011.

18. Abdulhadi, L. M., Kasiapaan, dan Saad. (). Residual Alveolar Ridge Resorption in Completely Edentulous Patients Influenced by Pathophysiologic Factors. Dentika Dental Journal, 2009: Vol. 14(1) .

19. Campbell, R. L. (1960). A Comparative Study of the Resorption of the Alveolar Ridges in Dentureweares and Non-denture-weares. J Am Dent Assoc.

20. Samkyuta, dan G, D. (2016). Residual Ridge Resorption in Complete Denture Weares. Journal of Pharmaceutical Sciences and Research .

21. Babu, D., Jain, V., Pruthi, G., Mangtani, N., dan Pillai, R. S. (2017). Effect of Denture Soft Liner on Mandibular Ridge Resorption in Complete Denture Weares after 6 and 12 months of Denture Insertion: A Prospective Randomized Clinical Study. The Journal of Indian Prosthodontics Society.

22. Jayaram, B. S., Analysis of Mandibular Ridge Resorption in Completely Edentulous Patients using Digital Panoramic Radiography. J.Dent.Med.Sci. 2017.

23. Al-Sheikh, H., et al., Mandibular Resdiual Ridge Height in Relation to Age, Gender and Duration od Edentulism in a Saudi Population: A Clinical and Radiographic Study. Saudi Dental Journal. 2018.

24. Ribeiro, J. A., de Resende, C. M., dan Lopes, A. L., The Influence of Mandibular Ridge Anatomy on Treatment Outcome with Conventional Complete Dentures. Acta Odontal. Latinoam. 2014.

25. Celebic, A., et al., Factors Related to Patients Satisfaction with Complete Denture Therapy. Journal of Gerontology. 2003.

26. Zeng X, et al., Contribution of Edentulous Mandibular Alveolar Ridge Height and Denture Adhesive to Complete Denture Denture Retention. Journal of Biomedical Engineering. 2011.

27. Pan, S., et al., Does Mandibular Edentulous Bone Height Affect Prosthetic Treatment Success? Journal of Dentistry. 2010. 